\title{
Sistemas de información
}

\section{Algunas propuestas para propulsar la administración en línea. La biblioteca pública como portal de acceso al e- government}

\section{Por Glòria Pérez-Salmerón}

Resumen: Para alcanzar la revolución tecnológica en nuestro país es menester cubrir necesidades básicas como las telecomunicaciones, los contenidos en nuestras lenguas y un cambio en la administración que desarrolle el e-government. La administración debe revalorizarse de cara a la sociedad apostando por el cambio de cultura, formación de los administradores, sistematización de la tramitación administrativa e integración de sus bases de datos en un repositorio único. Debe aprovechar también la biblioteca pública como portal de acceso a la administración en línea, ya que es un equipamiento básico de cultura ya existente en el municipio y una alternativa sostenible para desarrollarla que da acceso a la información facilitando al ciudadano el conocimiento. La biblioteca está preparada para desempeñar un papel profesional y debe ocuparse también de gestionar la formación de las TI para que cualquier ciudadano pueda desenvolverse 


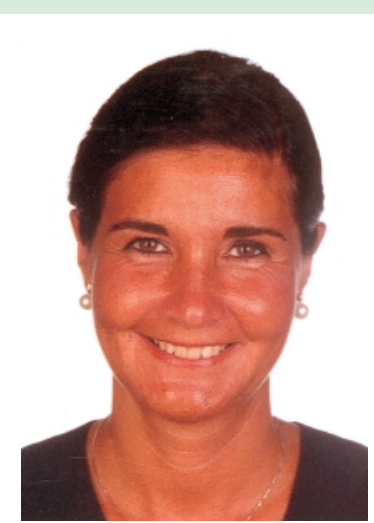

Glòria Pérez Salmerón es diplomada en Biblioteconomía y licenciada en Documentación por la Univ. de Barcelona, así como postgraduada en Gestión de bibliotecas por la Univ. Pompeu Fabra. Fue directora de la Biblioteca central urbana de Badalona, coordinadora de las bibliotecas del Barcelonés Norte y delegada de Unet (Unesco model library) hasta febrero de 2001, fecha en la que se puso al frente de la Sección de Procesos Técnicos del Servicio de Bibliotecas de la Diputación de Barcelona. Actualmente es vocal de la Junta del Collegi Oficial de Bibliotecaris i Documentalistes de Catalunya.

fácilmente en un entorno electrónico evitando la fractura digital.

Palabras clave: Administración en línea, E-government, Repositorio único, Biblioteca pública, Fractura digital, TI, Intranet, Extranet, Contenidos.

\section{Title: Proposals for promoting online public administration: the public Iibrary as gateway to e-government}

Abstract: To achieve a technological revolution in this country, changes must be made to assure that basic needs are covered, such as a solid telecommunications infrastructure, the availability of contents in the official languages, and a renewed public administration capable of developing e-government. Changes are needed for renewing organisational culture, revamping professional staff training, systematising official procedures, and integrating public databases into a single repository. The public library should serve as the gateway to e-government, since it is a basic municipal service that already exists and currently provides knowledge access to citizens. The library is ready to assume this new professional role, which should include IT training to allow citizens to feel comfortable with new technologies, thereby avoiding the digital divide.

Keywords: E-Government, Repository, Public library, Digital divide, IT, Intranet, Extranet, Contents.

CUANDO YA HACE UN PAR DE AÑOS largos que los expertos consideran que estamos en los albores de la sociedad del conocimiento o de la comunicación', la realidad que vive nuestro país nos muestra que sólo estamos asomándonos a las prácticas iniciales de la ya internacionalmente adulta sociedad de la información.

La lectura de la realidad nos muestra 3 factores limitadores: primero debemos reconocer que los indicadores sobre conexión a internet en los hogares españoles están muy por debajo de la media deseable. El recién aparecido informe de la Comisión Soto ${ }^{2}$ destaca que el $54 \%$ de los ciudadanos no tienen PC en su casa y que el $48 \%$ de las empresas no extraen el máximo rendimiento de las TIC por causas relacionadas con la falta de información. En segundo lugar, la poca formación que han recibido los usuarios en tecnologías de la información, en especial el público adulto y mayor. Por último, el poco esfuerzo que hasta hace muy poco la administración ha puesto en dotar a la Red de contenidos en nuestras lenguas y especialmente en fa- cilitar las gestiones en línea. Por tanto, podemos diagnosticar con claridad que estamos en una fase manifiestamente inicial y necesitamos, con urgencia, planificar la estrategia para afrontar el reto tecnológico y sobre todo poner en marcha un plan director que tenga en cuenta cómo abordar el reto de forma integral. La citada Comisión Soto ha propuesto impulsar un nuevo plan que vendrá a sustituir a Info XXI; esperemos que esta vez las propuestas cuenten con los medios económicos necesarios y se concreten en acciones a corto plazo.

\section{¿Cómo se puede abordar el reto?}

Es larga la lista de necesidades que se observan para conseguir que nuestra sociedad funcione con normalidad en un entorno digital sin fracturas considerables y, para conseguirlo, un buen plan estratégico tendrá que satisfacer absolutamente todas ellas.

Un aspecto para avanzar a grandes pasos y lograr la revolución tecnológica es sin duda alguna el e-government o administración en línea. El gobierno, además, no debe olvidar otros factores co- mo potenciar los contenidos en castellano, catalán, euskera y gallego, así como facilitar el acceso de inmersión a nuestra sociedad en las otras lenguas de los nuevos españoles.

Considero prioritario empezar por las infraestructuras de las comunicaciones. Aunque suene mal, debemos de admitir que en muchos casos éstas son inexistentes en gran parte de nuestra geografía. Es evidente que los ciudadanos no se pueden conectar si no hay líneas de conexión y esto, aunque parezca mentira, ocurre más allá de lo que a simple vista vemos, cegados por un mar de anuncios vistosos en los medios de comunicación. Quizás, si la legislación fuera más contundente en este sentido, sería más fácil obligar a los que comercializan las comunicaciones a cubrir todo el territorio.

\section{E-government, ¿qué aspectos aún no ha tenido en cuenta la administración?}

La administración ${ }^{3}$ en general ha ido integrando las TI a sus procesos desde un planteamiento de mejora de herramientas. Es decir, 
las ha incorporado como nuevas herramientas con muchas más prestaciones (eso sí) que las antiguas máquinas de escribir, al modelo tradicional de trabajo burocrático y de oficina. Desgraciadamente no ha sido capaz, aún, de aprovechar la oportunidad que nos brindan para analizar en profundidad el porqué del modelo tradicional de trabajo y cuestionarse uno por uno sus procesos y subprocesos, para redefinir qué es necesario mantener y qué hay que rehacer para ajustarse a las dinámicas que piden los tiempos que vivimos; es lo que en el mundo empresarial se denomina reingeniería de procesos, término ya caduco para muchos expertos, pero que empleo por considerarlo muy aclarativo para entender la nueva redefinición de procesos aplicando las medidas correctivas como resultado del basto análisis.

En definitiva, nuestra administración, heredera de la francesa, ha copiado el modelo manual pasándolo al tecnológico sin analizar qué debía dejar de hacer o qué incorporar para convertirse en organización estratégica, porque no hay que olvidar que la administración, la primera industria del país y por lo tanto motor del cambio, está perdiendo el tren de la competitividad. ¡Qué lástima de oportunidad!

Sin duda alguna, sin este cambio profundo nuestra administración se está convirtiendo en un paradigma de organización anticuada, sobre todo lenta en el ritmo de respuesta a los ciudadanos en las cuestiones consideradas como elementos básicos característicos de esta sociedad actual, la independencia de las distancias y la rapidez en la comunicación. La clave del éxito del nuevo modelo debe volcarnos a una sistematización de la tramitación administrativa dejando en el camino, si cabe, todo lo que no sea estrictamente necesario tramitar.

\section{La formación de los administradores: otro factor clave que no hay que olvidar}

La administración requiere de profesionales capacitados en las TI, pero además es necesario un cambio de cultura que los acerque a un perfil más agresivo, más operativo desde el punto de vista de resultados inmediatos.

Sin ánimo de entrar en debate y reconociendo excepciones notables que se han esforzado en actualizar este punto débil, me gustaría poner de manifiesto que, en general, la actual gestión anticuada y el encasillamiento que representan las estructuras orgánicas de nuestras administraciones, con flujos de información verticales, son un verdadero lastre.

\section{«Hay que dise- ñar servicios de respuesta a los ciudadanos y también a las empresas, la so- ciedad en gene- ral tiene que sa- ber que la admi- nistración tam- bién está a su servicio»}

Éste es otro factor que sin duda hay que apuntar como estratégico para abordar el reto. Hoy día todos los miembros de una organización deben aportar ideas, tener una visión global para contribuir al desarrollo de "su organización" y huir de las actitudes compartimentadas.

Si queremos que la administración cambie hay que apostar fuerte para que sus agentes, los administradores, también lo hagan y, por lo tanto, es prioritario formar a los trabajadores. Es necesaria y urgente una formación en gestión, los trabajadores deben conocer qué procesos son estratégicos, cuáles son clave y qué responde sólo a acciones de soporte, y trabajar con detalle los factores competenciales para dar valor a la organización (yo diría revalorizarla).

Hay que tener en cuenta también que en las unidades administrativas pequeñas, como son los ayuntamientos de municipios con un índice de población bajo, sería conveniente dar una formación en gestión a sus cargos políticos, ya que en muchas ocasiones son ellos los que actúan como administradores.

Trabajar la horizontalidad de la información en la administración pasa por el inexcusable desarrollo y utilización de las intranets y extranets corporativas y la comprensible descomposición de la prestación de servicios a diferentes niveles. Hay que diseñar servicios de respuesta a los ciudadanos y también a las empresas, la sociedad en general tiene que saber que la administración también está a su servicio.

\section{Necesidad de un repositorio único de datos}

Sin duda alguna la administración debe llegar cuanto antes a la integración de sus bases de datos y aprender del modelo bancario, que ofrece un servicio único de red multicanal y multigeográfica. Es necesario que se aplique en la integración de las diversas bases de datos -que actualmente mantiene duplicando esfuerzos propios y de los ciudadanos- en una sola, potente y competitiva. Los ciudadanos no entienden la falta de diálogo entre los compartimentos administrativos y las peticiones que le formula la administración. Ejemplos como: "tráigame un certificado del piso de arriba, lleve este otro al edificio de al lado", son difíciles de digerir frente al fácil estilo, eficaz y eficiente del sistema bancario. Los bancos han sabido 
tener un repositorio único. ¿Por qué no aprendemos de ellos?

Existen algunas iniciativas de acceso único a la administración como el que presenta $\mathrm{Cat}_{365^{4} \text {, un }}$ portal unificado a través del cual los ciudadanos pueden gestionar los servicios de todas las administraciones públicas catalanas. Es urgente que cunda el ejemplo.

\section{Hay que apostar por los equipamientos existentes}

Por otro lado, la descoordinación entre los diferentes niveles (local, supralocal, autonómico y estatal) de nuestra administración provoca que en algunos casos se ofrezcan servicios duplicados a los ciudadanos o bien que se dejen de prestar. En vez de sumar recursos y esfuerzos para ofrecer servicios de calidad, se dispersan, no sólo voluntades en la gestión de la información, sino también recursos económicos. Se da la paradójica situación de inaugurar centros de acceso a las tecnologías de la información para los ciudadanos, sin tener en cuenta la existencia de otros equipamientos similares ya en funcionamiento, como las bibliotecas públicas, además de los archivos, que están desarrollando un papel creciente en la aplicación de sistemas de gestión documental. Analistas de la sociedad de la información como Moore ${ }^{5}$, Majó ${ }^{6}$, o Cornella $^{7}$, incluso Postman ${ }^{8}$, ante el estudio de las ventajas y los riesgos que presenta esta sociedad, consideran las bibliotecas públicas una herramienta clave para extender las ventajas entre toda la población y minimizar algunos riesgos.

La biblioteca pública es por ley $^{9}$ el equipamiento básico de cultura en el municipio y debe ofrecer, según su marco conceptual ${ }^{10}$, el acceso a la información que facilite al ciudadano el conocimiento y la información local y de la comunidad. Es necesario entender que, además de ser agente mediador entre la información y el ciudadano, dispone de equipos de profesionales con habilidades para añadir valor a la información, y por lo tanto que ayudan a conseguir que el servicio bibliotecario se convierta en servicio proveedor de conocimiento.

Por otro lado, desde la cooperación bibliotecaria, utilizando patrones comunes de descripción normalizada, la biblioteca es capaz de gestionar la información de su entorno $\mathrm{y}$, utilizando protocolos internacionales comunes (como son el formato marc o el protocolo

\section{Desde enero del año 2002 Swets \& Zeitlinger Publishers,} editora de esta revista, ha encargado la distribución de todas sus publicaciones a la siguiente empresa del grupo Swets \& Zeitlinger:

Turpin Distribution Centre. Blackhorse Road, Letchworth, SG6 IHN, Herts, Reino Unido.

Tel.: +44- I 46267 2555; fax: I 462480947

subscriptions@turpinltd.com

Rogamos a nuestros suscriptores que para solventar cualquier asunto administrativo se dirijan siempre directamente a Turpin. Sin embargo recordamos que continúan en funcionamiento los números de teléfono de atención al suscriptor en Barcelona:

Tel.: +34-932 70। I44; fax: 93270 I l45
$\left.\mathrm{Z} 39.50^{11}\right)$ compartir con el resto de centros la lectura y la reproducción de esta información como si se utilizara un repositorio único.

La biblioteca pública es un servicio de proximidad y además de dar servicio a los usuarios que viven en su área de influencia, con una buena dotación tecnológica puede convertirse fácilmente en plataforma de acceso a las tecnologías de la información y, por supuesto, en portal de acceso a la administración en línea. Las bibliotecas públicas de Girona, Lleida y Tarragona ya están ofreciendo desde sus propias webs el acceso al portal CAT365 para facilitar el egovernment a los ciudadanos a los que prestan sus servicios.

El Servicio de Bibliotecas de la Diputación de Barcelona en el primer semestre de 2001 organizó un programa de cursos de formación en TI y recursos en internet en 12 bibliotecas municipales que trabajan en la red provincial. Estaba dirigido al público adulto con el objetivo de iniciar a los ciudadanos en la navegación por internet y a sentirse cómodos en el entorno digital. Se impartieron 55 cursos, 33 de carácter general, pensados para todo tipo de usuarios y 22 dirigidos a profesionales de diferentes sectores. Se tuvo en cuenta que el contenido de los cursos fuera suficientemente atractivo y que los recursos mostrados fueran de ámbitos diversos para captar diferentes intereses. Además, se ofrecieron adrede los sábados por la mañana para favorecer que pudieran acudir los ciudadanos activos.

Más de 500 usuarios participaron en esta primera experiencia y puede afirmarse que ha servido de impulso para que, con posterioridad, muchas bibliotecas (entre las que se cuentan las de Barcelona ciudad, Igualada, Les Franqueses del Vallès, Sabadell y Terrasa) organicen periódicamente iniciativas similares y participen activamente 
en la formación inicial tecnológica de muchos ciudadanos de sus municipios.

Desde mi perspectiva, la biblioteca pública tiene un papel principal en la contribución activa a que cualquier ciudadano pueda desenvolverse fácilmente en un entorno electrónico. Además de ocuparse de gestionar la formación en TI y de convertirse por si misma en agente formador e impulsor de su uso, es necesario que también la consideremos una alternativa sostenible para desarrollar la administración en línea.

La biblioteca puede contribuir intensamente a que no se produzca fractura digital dando acceso a aquellos ciudadanos que no disponen de conexión en su domicilio, facilitándoles, además de la consulta de los recursos-e de información, el acceso a los servicios que la administración les ofrece a través de internet.
En este sentido me gustaría hacer una llamada a los bibliotecarios y gestores de la información para que propongan y convenzan a las autoridades competentes de sus municipios de que las bibliotecas públicas, más allá de ofrecer sus propios servicios bibliotecarios y de información en línea a través de sus interfaces web, deben y pueden aportar otras opciones de servicios como el de tramitación administrativa.

\section{Notas}

1. Término empleado por Salvador Cardús en la conferencia inaugural de las 8es Jornades catalanes de documentació, celebradas en L'Hospitalet de Llobregat, 15-16 de noviembre de 2001.

2. Informe de la Comisión Soto por encargo del Ministerio de Ciencia y Tecnología. Consultado en: 02-04-03.

http://www.mcyt.es/asp/ministerioinforma/prens a/np01-04-03.htm

3. Entiéndanse todas nuestras administraciones a nivel local, supralocal, autonómico y estatal.

4. Proyecto Cat365, Administració Oberta de Catalunya, promovido por la Generalitat de Catalunya y Localret (Consorci d'Ens Locals Catalans). Consultado en: 26-02-03. http://www.cat365.net
5. Moore, Nick. "La sociedad de la información”. En: Informe mundial sobre la información. Madrid: Unesco/Cindoc, 1997, p. 295.

6. Majó, Joan. Xips, cables i poder. Barcelona: Proa, 1997.

7. Cornella, Alfons. "Economia de la informació o societat de la informació". En: Barcelona management review, 1998, mayo-junio, n. 8, pp. 15-31.

8. Postman, Neil. Tecnópolis: la rendición de la cultura a la tecnología. Barcelona: Galaxia Gutenberg, 1994.

9. Ley de Bases de Régimen Local (7/1985).

10. Manifiesto de la Unesco de la biblioteca pública 1994 y Directrius Ifla/Unesco per al desenvolupament del servei de biblioteques públiques: elaborades per un grup de treball dirigit per Philip Gill per encàrrec de la Secció de Biblioteques Públiques. Barcelona: Col-legi Oficial de Bibliotecaris-Documentalistes de Catalunya, 2002. Consultado en: 26-02-03. Versión en castellano:

http://unesdoc.unesco.org/images/0012/001246 /124654s.pdf

11. About the Z39.50 Gateway. Consultado en: 26-02-03.

http://lcweb.loc.gov/z3950/gateway.html

Glòria Pérez-Salmerón, jefa de la Sección de Procesos Técnicos del Servicio de Bibliotecas de la Diputación de Barcelona. perezsg@diba.es 